\title{
Culturally Responsive Practices in a Diverse Elementary Classroom: A Case Study
}

\author{
Shernavaz Vakil \\ Weber State University, USA \\ Lynn Atkinson Smolen \\ University of Akron, USA \\ Jennifer Campbell \\ Westlake City School District, USA \\ Melina Alexander \\ Weber State University, USA
}

\begin{abstract}
The population in the US continues to grow more diverse leaving schools to face the challenge of meeting the needs of students from varied linguistic backgrounds. In order to create successful learning experiences for English learners from culturally and linguistically diverse backgrounds, teachers need to be educated in culturally responsive pedagogy including understanding their students' backgrounds, creating positive learning environment, using culturally relevant strategies, and fostering positive home school relations. This article presents a single participant case study as described by Merriam (2009), where one teacher provides her experience implementing culturally responsive practices in her classroom after participating in a TESOL (teaching English to speakers of other languages) professional development program.
\end{abstract}

Keywords: English learners, culturally responsive pedagogy, case study, diversity, learning environment

\section{Introduction}

As the US population grows more diverse, public schools face the challenge of meeting the needs of an increasing number of culturally and linguistically diverse (CLD) students. This is especially evident in urban inclusive classrooms where the number of students from diverse backgrounds is increasing, but their educational performance remains below their potential (Ford et al., 2014; Hoover, 2012). Addressing students' diverse needs is a challenging task no matter where the children are educated or what types of strategies are used. Despite these circumstances, many educators and other professionals are striving to make improvements to benefit CLD children in the classroom. Placing diverse students in the general education classroom will not translate directly into effective learning for children unless appropriate 
responsive practices are implemented by educators. To be effective, educators need to create meaningful learning experiences (Lerner et al., 2003).

A single case study research design (Merriam, 2009) was used for this study in order to gain an understanding of critical factors impacting culturally responsive practices for English language learners in the general education classroom. The study was conducted in a diverse school district in the midwestern United States. Interviews and observations were conducted in order to understand the experiences of one classroom teacher's implementation of culturally and linguistically responsive practices after participating in a federally funded TESOL (teaching English to speakers of other languages) program.

This study employed a constructivist theoretical framework based on the belief that people create meaning by filtering new information and reconciling it with their current ideas and experiences (Meyer, 2009). The constructivist perspective was suited to this case study because the authors sought to determine how one teacher reconciled her previous professional knowledge and new learning to make changes to her classroom. The constructivist approach is also compatible with the researchers' beliefs that human beings develop knowledge and make sense of the world when comparing new experiences with their existing schemata (Appleton \& King, 2002).

\section{Case Study}

This case study focuses on the experience of Ms. Smith, a $4^{\text {th }}$ grade teacher in a school district located in the midwestern United States. This district has four neighborhood elementary schools, a middle school, an intermediate school, and a high school. There are 3,685 students enrolled in kindergarten through twelfth grade. The racial demographics in this district consist of $85.7 \%$ White, $2 \%$ Black, $6 \%$ Hispanic, $6.3 \%$ Asian, and $1 \%$ Indigenous. Five percent of the students are classified as English learners primarily with native languages of Arabic and Spanish. At the time of this project, Ms. Smith had been a teacher for ten years. She received her teaching license in elementary education and had taught grade levels P-K through $4^{\text {th }}$ grade.

Ms. Smith participated in a five year long national professional development grant established by The US Department of Education. This grant included a TESOL endorsement program for preparing general education teachers to use research-based content pedagogy addressing the needs of English learners (Els). The program balances theory and practice, uses the Sheltered Instruction Observation Protocol (SIOP) model as a framework, and emphasizes national standards and research-based practices for teaching academic language and subject areas (Echevarría et al., 2013). The program was designed to focus on preparing content area 
teachers and special education teachers who teach Els to develop effective instruction using culturally responsive practices to meet their needs. The program is organized to meet the critical need to prepare teachers to accelerate the language development and academic achievement of Els.

During this program, Ms. Smith's $4^{\text {th }}$ grade general education class consisted of 27 students with the following racial backgrounds: 20 White, three Hispanic, one Asian, and three mixed race. There were 14 boys and 13 girls in the classroom. According to Ms. Smith, in her interview, this group of students was sociable, active and inquisitive. They loved to use creative avenues to express their knowledge (3D projects, posters, and plays) and enjoyed using technology to support or demonstrate their learning. For this case study class, Ms. Smith used several strategies such as explicitly linking background knowledge and past learning to lesson content, using visuals from their native country, paraphrasing, contextualizing definitions, and slowing speech, learned through the TESOL program to create a culturally responsive classroom.

\section{Culturally Responsive Pedagogy}

Culturally responsive pedagogy (CRP) is based on the foundation that learning, rather than occurring in a void, is most effective when learned through the lived experiences of the student. The characteristics, prior experiences, cultural knowledge and perspectives of diverse students form the frame of reference through which learning is most effective (Gay, 2002). Culturally responsive teaching offers ways to best support diverse learners in the classroom by looking at the whole child. Students are empowered intellectually, socially, emotionally and politically by using cultural and linguistic referents to impart knowledge, skills and attitudes (Ladson-Billings, 2009). CRP enhances the learning experiences of CLD students by focusing on their cultural knowledge, prior experiences, frames of reference and performance styles.

However, teachers often do not recognize the impact of diversity and the need for culturally responsive practices in their interactions with CLD students (Dray \& Wisneski, 2011).

While diversity itself is not an issue, the potential cultural mismatch and dissonance between teachers who are largely white (American Association of Colleges of Teacher Education, 1999) and CLD students can be a concern (Dray \& Wisneski, 2011; Ford et al., 2014). This dissonance often results in lower expectations and the disproportionate representation of minorities who have academic failure, resulting in placement in special education (Ford et al., 2014; Sorrells, et al., 2004). 
It is imperative for teachers to move beyond approaches such as simply celebrating holidays to deliberately planning and integrating culturally relevant practices in the classroom (Gay, 2010). This is especially relevant to linguistically diverse students who not only speak another language but who may also contextualize information from a different frame of reference (Gay, 2002; Klinger \& Gonzalez, 2009; Worrell, 2007).

\section{Case Study: Culturally Responsive Pedagogy in Context}

Having taught $4^{\text {th }}$ grade for four years in her district, Ms. Smith became aware that the school population was becoming more diverse with immigrant children and Els. With this change in the school population, she became more aware of the differences between her sociocultural background and that of the diverse students in her classroom.

Ms. Smith was aware that to be culturally responsive she needed to be critically conscious of her own cultural socialization and its impact on her attitudes and behaviors that shape the classroom. To be critically conscious she reflected on her own attitudes and biases, recognizing that these may impact of her assumptions, resulting in the inequitable treatment of CLD students in inclusive classrooms (Weinstein et al., 2004). Thus, she knew that in order to be culturally competent she needed to acknowledge her own positionality while honoring students' cultural backgrounds. She became more aware of how her expectations were guided by her own culture and that her expectations may differ from those of CLD students in their classroom. It was therefore critical that she not only had knowledge of her students' backgrounds, but also integrated this knowledge into her instruction (Ford et al, 2014; Gay, 2010).

Ms. Smith came to this realization when she heard two students talk in Arabic with excitement and interest. She realized that she did not allow her Els to speak in their native language unless it was to communicate in the classroom. She also realized that she spoke about their history and historical figures from a US perspective rather than inviting them to share their knowledge.

Acknowledging the mismatch between her background and her students' backgrounds, Ms. Smith recognized that she needed to learn more evidence-based strategies to support them. This included educating herself about her students' cultures, languages, and perspectives; and how to best create a culturally responsive environment in her classroom that affirmed their cultures, language and experiences. She recognized that learning key concepts in the school curriculum would be most effective and meaningful if she connected the concepts both through the students' cultural perspective and at their ability level. 


\section{Culturally Responsive Learning Environments}

Culturally responsive teaching creates learning environments that affirm students' cultures and experiences and encourages them to value cultures and experiences different from their own (Ladson-Billings, 2009). This implies that the learning environment created by teachers meets students at their point of need rather than at their grade level (Worrell, 2007). According to Hoover (2012), to maintain cultural integrity in the classroom, the guidelines determined by the Center for Research on Education, Diversity and Excellence are: (a) functional language in the classroom to promote academic competence, (b) home community partnerships to optimize contextual learning, (c) cooperative learning, (d) verbal interactions and communications which encourage academic/instructional conversations and I a challenging curriculum which holds everyone to high expectations. These form the basis for connecting instruction to students' frames of reference.

The challenge for teachers is not the content itself, which is often factual, rather, it is the ability of teachers to teach content through the cultural lens of the students thereby enhancing their understanding of content (Gay, 2002). Creating culturally responsive learning environments begins with infusing a rich multicultural education reflecting the diversity of the classroom and the uniqueness of its students.

Culturally responsive teachers (CRTs) connect with learners by using their experiences to differentiate and scaffold instruction, and to encourage verbal interactions and discussions to promote understanding of key concepts (Klinger \& Gonzalez, 2009). CRTs value the connection between new learning and prior knowledge and experiences of their CLD students (Ford et al., 2014; Ladson-Billings 2009). Additionally, instruction is supported through various delivery modes including teacher modeling using think alouds, demonstrating completion of tasks and including visual representation of content rather than lecture alone. Diversity is affirmed through books by authors representing the diversity in the classroom, bulletin boards with multicultural displays, activities that support culturally responsive practices such as promoting conversations on the impact of diversity and its influences on the students (Ford et al., 2014).

\section{Case Study: Creating Culturally Responsive Learning Environments}

First of all, Ms. Smith's classroom was designed with the students in mind. A section of the classroom was dedicated to whole group learning, two large tables allowed for smaller group learning, and individual desks were provided. The room also included a quiet corner for 
individual breaks, a variety of stools and seats that could be moved around the room to encourage partner work and a technology corner.

A classroom library consisted of a large bookcase against one of the classroom walls which included many nonfiction and literature books at various reading levels available for students. Visual supports including the Daily Schedule, I Can statements, classroom and group expectations, a math word wall and reading strategies were posted on the walls. The positive environment that she created allowed the students to feel respected, responsible, and safe to share ideas and opinions.

Further, an example of creating a culturally responsive learning environment came from an observation during Ms. Smith's $4^{\text {th }}$ grade unit on immigration that was related to the State Social Studies Standard: Various groups of people have lived in [this state] over time including American Indians, migrating settlers and immigrants. Interactions among these groups have resulted in cooperation, conflict and compromise. To address this standard, her goal with this unit was to teach about immigration in the past as well as immigration today. She not only wanted to teach the students their state's history involving immigration but also to incorporate into the unit how people are still immigrating to the state. Thus, this unit made a meaningful connection to the immigrant children in her classroom and helped the other students develop awareness and appreciation of the immigrant experience.

To introduce the unit, Ms. Smith activated students' background knowledge and pretaught subject specific and general academic vocabulary. She began by focusing on the word immigrant (immigrating, immigration). She asked the students to discuss with each other what they knew about immigration. To deepen the students' understanding, Ms. Smith showed a short video about people traveling to the United States in 1903. The video helped students visualize what the word immigrant means and encouraged a lively discussion. When she asked if immigrants still travel to America today, many students were unsure. Half of them said yes and the other half said no or did not know the answer. She then proceeded to show another short video about a young girl who recently immigrated to the United States (http://teacher.scholastic.com/activities/immigration/ young immigrants/taylor.html). Having been presented with a specific example of an immigrant, the students then compared their own experiences to those of the girl and shared personal stories of people they knew who had immigrated to the United States. The depth of these responses and student participation clearly exemplified how engaging in CRP leads to increased student achievement.

Next, Ms. Smith introduced students to a newspaper article on immigration which formed a key part of a nonfiction lesson on text features; main idea and supporting details; and 
summary writing. These activities were followed up by discussion of non-fiction articles on immigration in differentiated groups. The students also played "What's my Title?," a game in which they matched titles of articles to the main idea, rewrote titles from short articles from National Geographic for Kids, and created Wordle designs on the computer for the main idea and supporting details in the articles they read.

Throughout the unit, Ms. Smith had students work with partners. For example, she had students work with a partner to mark the headings and subheadings of the newsletter, to complete the graphic organizer and to discuss the text features they found in the newsletter. Ms. Smith had learned about the effectiveness of peer interaction when studying the SIOP model in the TESOL program. She believed that it provided her students with valuable opportunities to practice their listening and speaking skills and found pair work was particularly beneficial for the CLD students in her classroom.

Additionally, Ms. Smith grouped students in a variety of ways based on the objectives being presented. In math, students were grouped based on their pretests for each unit. Activities within the math class were then based on the activity planned and the outcome wanted. Groups were based on ability, student support, random grouping, and interest. Ms. Smith also gave students opportunities to teach and reinforce concepts. In language arts, students were also grouped in various ways. Reading groups were based on reading abilities which allowed for differentiated reading material and higher order thinking questions to be incorporated. Whole class instruction included opportunities to model activities, pair and share, provide opportunities among teacher and students, and encourage content discussion. Small and large group activities were randomly selected or carefully configured to include different reading and speaking abilities within groups to support language and content goals.

Ms. Smith also altered her daily lessons based on the results she saw by using the SIOP model. She made sure she explicitly taught vocabulary words and elicited background knowledge. She also made sure many opportunities were available for students to practice and apply both the academic content and language objectives and included scaffolding into the lessons. CRTs provide students with the language and content objectives for a lesson so that they know what the purpose of the lesson is and what they are expected to achieve in the lesson, thus helping them to develop more independence as learners. When teachers provide English learners with the objectives of a lesson, they empower them to be more self-directed and have a positive mindset. This connects to an important tenet of CRP: teachers simultaneously support and challenge students (Snyder \& Staehr Fenner, 2021). Instruction Checking 
Questions (ICQ's) and additional visuals were incorporated into her lessons, and objectives were made clear and were referred to often.

Assessments were created to meet the objectives and lessons were planned around them. She found that posting content and language objectives throughout the entire lesson benefited both her and her students. She referred to the objectives more often and was able to show how and why the activities and lessons connected to the curriculum goals and standards. Including language objectives, also allowed students to focus on how they would convey what they had learned and show how they applied the new information. A component of CRP is allowing students to take ownership of their learning (Gay, 2010). By allowing students the opportunity to show how they apply new information, Ms. Smith gave students dominion over their knowledge acquisition, establishing a learning environment grounded in culturally responsive practice.

Prior to the TESOL program, Ms. Smith often offered examples that reflected or represented diversity in general but were not specific to the diversity of the students in her classroom. While she often shared a picture book that included characters or photos of people from different races she did not read or show any multimedia materials that included any aspects of their culture.

When trying to activate background knowledge, she now deliberately searches for examples in the Els native language or uses photos that explicitly link the new concepts to the students' background knowledge. For example, she tried to link the word "plantation" to the classes' background knowledge by building off the word "farm." Two of her Els did not have any prior knowledge of the word "farm" so she altered her lesson to include photos of "gardens" with flowers from their land of origin. The students were then able to build off the word "garden."

Additionally, for the Spanish speaking students, she built off the Spanish word granja (farm) to gain understanding. It was not that those students did not have any background knowledge of a farm, but that they just were not familiar with the English word "farm." By incorporating photos and words from student's native languages, she assisted the Els to have a clear and meaningful understanding of the vocabulary and support them with linking new concepts to their own background experience.

\section{Culturally Responsive Strategies}

Teaching and learning do not occur in a vacuum and are cultural processes occurring in social contexts which are influenced by teachers' and students' values, beliefs and attitudes 
and influence the decisions and actions teachers and students take (Gay, 2002). Culturally responsive strategies empower students academically and socially as educators deliberately integrate cultural references into instruction and the curriculum (Ladson-Billings, 2009).

Lucas et al., (2008) have identified linguistically responsive pedagogical practices teachers need to use to facilitate learning of the curriculum by Els (pp. 366-370). These pedagogical practices are the following:

1. Teachers need to learn about ELs. They need to know about the backgrounds and languages of their ELs. They also need to understand that ELs are not a homogeneous group. They enter U.S. schools with varying levels of oral proficiency and literacy in English as well as prior knowledge of different subject matter.

2. Teachers need to identify the language demands inherent in classroom tasks. They need to be aware of the language proficiency levels of their ELs and the challenges inherent in the tasks they give their ELs. This is essential for them to know in order to be able to determine if scaffolding is necessary, the extent to which scaffolding is necessary, and how best to scaffold language and content for their ELs.

3. Teachers need to know about a variety of different strategies and tools they can use to scaffold learning for ELs. This includes ways to minimize ELs' anxiety about being a second language learner in a mainstream classroom. "They can do so by establishing and enforcing classroom rules that respect all students, minimize competition, and encourage cooperation" (Lucas, et al., 2008, p. 369).

In addition to pedagogical practices described by Lucas and colleagues, teachers of ELs need to know how to use CRP for linguistic, sociocultural and academic purposes (Staehr Fenner \& Snyder, 2017). Staehr Fenner and Snyder developed a model that synthesizes characteristics of CRP into four overarching guidelines. They discuss this model in relation to the importance of providing ELs with an equitable education. The guidelines are summarized below.

Guideline 1: Culturally responsive teaching is assets-based. Often educators have a deficit view of ELs, seeing them as students who have hurdles to overcome. They frequently think their home languages and cultures are impediments they need to surmount. This viewpoint is likely to produce low-self-confidence and lack of motivation.

In contrast, an assets-based perspective views students' cultures and languages as valuable foundations for learning the new language and academic content (González, 2005; Staehr, Fenner \& Snyder, 2017; Valencia, 1997; Valenzuela, 1999). In a similar way, an assetsbased perspective recognizes that ELs' parents support their learning and value their education 
even though it may not be evident to the school. In addition, an assets-based perspective opens teachers' minds to including students' background knowledge, experiences and knowledge into the curriculum (Staehr Fenner \& Snyder, 2017). For example, assigning students to interview a family member and then writing a biography on the family member based on the information that was collected, is one-way students' background experiences could be included in an English language arts unit on writing biographies.

\section{Guideline 2: Culturally responsive teaching places students at the center of the learning.}

Student-centered learning provides opportunities for students to learn from each other, rather exclusively from the teacher. One important way that this can occur is by explaining learning goals in ways students can clearly understand them so that they can participate in setting their learning goals and assess their own progress in reaching those goals (Stiggins et al., 2006). An excellent example of student-centered learning is cooperative learning.

Guideline 3: Culturally responsive teaching values students' languages, cultures, and backgrounds.

This guideline emphasizes the importance of teachers valuing and respecting students' cultures, languages and experiences and looking for opportunities to include those assets in teaching and learning in the classroom. Teachers can use this guideline by incorporating multicultural literature into the curriculum. For example, ELs can learn more about issues related to immigration by reading novels, such as Day of the Pelican (Paterson, 2010), Inside Out \& Back Again (Lai, 2013), Star in the Forest (Resau, 2012), and Shooting Kabul (Senzai, 2011), or picture books such as How Many Days to America? (Bunting, 1990).

Another way is for teachers to value the native languages and cultures of ELs (Staehr Fenner \& Synder, 2017). This can be done by supporting them in using their native language as a bridge to learning English by teaching them how to identify and use cognates (democracy, democracia), showing them how to use knowledge of their native language to build their proficiency in English, by learning the structural similarities between the two languages such as the similarities in morphology (nation, nación; dentist, dentista) and helping them seek support in the native language from peers when they struggle with learning a concept or skill in English.

\section{Guideline 4: Culturally responsive teaching simultaneously challenges and supports students.}

This last guideline emphasizes the importance of teachers having high expectations for ELs and challenging them to do grade level work while at the same time providing the necessary scaffolding for them to be successful (Staehr Fenner \& Synder, 2017). A good 
example of why this guideline is critical is the tendency for teachers to give ELs an easier text to read than the grade level text.

The problem with this strategy is that ELs will not learn how to tackle a challenging complex text unless they are taught how to do this and have practice doing it. A better approach than always giving ELs an easier text to read is to teach ELs how to do a close reading of a complex text while showing them how to use strategies that will help them successfully tackle the complex issues of the text. For example, the teacher could select a juicy sentence (complex sentence) from a text and show students how to chunk the sentence into parts, then use a graphic organizer to examine the parts and finally summarize each part. Teachers could also show them how to find the main clause of the complex sentence and interpret its meaning before they try to understand the dependent clauses and phrases in the sentence.

\section{Case Study: Using Culturally Responsive Strategies}

Ms. Smith learned that it was important to integrate culturally responsive experiences into regular lessons and to connect students' cultural backgrounds to teaching and learning. This represents Guidelines two (student-centered learning) and three (cultural foci) of Staehr Fenner and Snyder (2017) culturally responsive teaching model.

To help students feel that they were an important part of the learning community, she often asked them to share their personal knowledge and make connections to the content being taught. Recognizing that the concept of immigration was a social studies standard, she believed it was imperative to connect it with current immigrants to make it relevant to the immigrant children in her classroom. Before she began the immigration unit, Ms. Smith reached out to the newcomer EL boy in her classroom and asked if he would like to share his experiences coming to the US. Having no confidence in his English-speaking skills, he chose to do a PowerPoint that explained his viewpoints and experiences as a recent immigrant.

Ms. Smith worked one-on-one with him and used the opportunity to help him with some of the difficulties he had with English grammar, such as the confusion of he and she and verb tenses. This is an excellent example of Staehr Fenner and Snyder's (2017) Guideline one for CRP, an assets-based perspective, a view that honors students' cultural and linguistic backgrounds and integrates what students know and have experienced into the curriculum. Additionally, Ms. Smith encouraged extended time and the use of a language dictionary during both instruction and testing. This allowed her to focus on content knowledge rather than mastery of language.

Cooperative learning, an excellent example of Staehr Fenner and Snyder's (2017) 
Guideline two for CRP, provides opportunities for students of various abilities to work together to solve a problem. It involves small groups of different abilities assisting each other. When used appropriately, results can be positive, especially as it reinforces the skill for the student who has mastered the task. Crucial to the success of cooperative learning is that students work together in their group towards a common goal with differing roles assigned for participation (Berk \& Trieber, 2009). This provides students with diverse needs and abilities an opportunity to interact with other students in academic activities to learn from each other. It also helps them feel included in class activities. Ms. Smith used small groups to instruct throughout her lesson. This allowed her to differentiate her instruction to meet the needs of her students.

Based on what she learned, Ms. Smith revised her lessons to include a guided teaching component that used group or partner work as a scaffolding approach to prepare students for independent practice. By adding this step, Ms. Smith was able to check for understanding through observation, give individual support, and help students meet language and content objectives as they learned new academic vocabulary and concepts.

Another strategy that Ms. Smith found beneficial to all her students was how to teach and provide practice and review for vocabulary instruction. Earlier, Ms. Smith would go through the text and verbally provide the definition for the key vocabulary words and would also provide a few sentences that included the word. She realized she did not explicitly teach academic vocabulary, nor did she connect the words to prior knowledge or past learning. She began front loading vocabulary and then paraphrasing them throughout her lesson. While this strategy is not specifically addressed in Staehr Fenner and Snyder's (2017) model, it is a component of SIOP (Echevarría, et.al., 2013), a protocol used when working with students who are culturally and linguistically diverse.

Ms. Smith used both informal and formal assessments to guide her instruction and monitor student progress. She constantly checked for understanding through repetition, observations, conversations, and "thumbs up." Another strategy Ms. Smith learned was the importance of incorporating language objectives into the lesson and reviewing and assessing them at the end of lessons. She came to realize that constant checking for understanding of key vocabulary is just as important as checking for key concepts (Echevarría, et. al., 2013).

\section{Building Productive Home-School Relations}

Parent-school relations are socially constructed (Abrams \& Gibbs, 2002). Often, parent teacher interactions are based on the premise that teachers are the experts and parents are passive recipients of the interactions (Turnbull et al., 2015). However, for the most part parents 
are the first teachers for their children. With that in mind, schools need to access the knowledge parents bring to the school environment as well as the local community resources (Ford, 2004; Moll et al., 2005). When home-school collaborations deliberately emphasize equitable culturally responsive communications, there is respect, clarity and trust by both parties. Most importantly, it reflects a value for cultural and linguistic differences.

Meaningfully engaging with families through acknowledging their funds of knowledge strengthens the cultural competency of teachers with a positive impact on ELs (Díaz-Rico, 2013). Meaningful participation of CLD families of students in the learning process necessitates teachers critically reexamine their existing practices to identify overt and subtle patterns of exclusion of family engagement (Ford et al., 2016).

Strengthening teacher-parent communication and engagement begins with the need for teachers to reflect on their own biases and assumptions while recognizing the strengths of CLD families (Ford, 2004; Geenen, et al., 2001; Kim \& Morningstar, 2005). For example, many families from CLD backgrounds place greater value on non-verbal communication rather than verbal communication, which is often emphasized by teachers (Díaz-Rico, 2013). Rather than regarding communication and engagement from their own perspective, school personnel need to be willing to attend carefully to not only attend to the verbal messages given by parents, but also their non-verbal behaviors. Careful attention to these builds on parent-teacher collaboration and trust.

\section{Case Study: Fostering Positive Home School Relations}

Upon reflection, Ms. Smith realized she had an unconscious bias with respect to parent communication in her classroom. She assumed that everyone, including the CLD families preferred written communication shared either in print or by email. As a result, she often relied on her students to translate written communications for their families when it came to important documents. Both options did not allow for direct communication and information sometimes became skewed or lost in the translation. Reflecting on this, Ms. Smith realized that many of her CLD families understood the information better when communicated face to face which allowed them the chance to read non-verbal cues. When given the opportunity for verbal communication, she found them more responsive to supporting their children in the classroom. If written communication was necessary, Ms. Smith found CLD families responded better to written communication in text form as it allowed for information to be presented in small segments. Additionally, when required to provide written communication, Ms. Smith attached pictures or icons to support the content provided. This strategy followed guidelines 
recommended for facilitating communication for linguistically diverse students.

Another unconscious bias with Ms. Smith had related to her communication with CLD families was that she assumed that students and their families understood American national holidays and when they occurred. While her classroom newsletters included scheduled days off for holidays, the CLD students and families did not always understand the significance of the event or why it was an important day. Many did not understand the customs associated with the holidays such as "Turkey Day" referring to Thanksgiving Day. She also found that many CLD families were confused by the concept of "Teacher Work Day," a day often used for teacher professional development, and students do not attend school, since it literally means "the teacher is working." In addition, recognizing that written communication needed to be clearer for linguistically diverse families, Ms. Smith began to use more precise and simpler language with fewer idioms.

\section{Conclusion}

The population in US schools today is rapidly changing to include more CLD children. Given the documented benefits of culturally responsive practices for optimal student success, especially among ELs, teachers should be proactive in implementing culturally responsive practices which reflect the diversity of their schools and classrooms. Educators, who include all children in the learning process, promote a climate that increases sensitivity and acceptance of diversity while recognizing the wide range of abilities and learning needs of the diverse students in their classroom. In this article we have used a case study to demonstrate a teacher's deliberate journey towards being more culturally sensitive, inclusive and reflective in her instruction and communication with Els and their families.

\section{References}

Abrams, L.S., \& Gibbs, J.T. (2002). Disrupting the logic of home-school relations: Parent involvement strategies and practices of inclusion and exclusion. Urban Education, 37(3), 384-407.

American Association of Colleges of Teacher Education (1999). Teacher education pipeline IV: Schools, colleges and department of education. AACTE.

Appleton, J.V., \& King, L. (2002). Methodological issues in nursing research:

Journeying from the philosophical contemplation of constructivism to the methodological pragmatics of health services research. Journal of Advanced Nursing, 40(6), 641-648. 
Berk, R.A., \& Trieber, R.H. (2009). Whose classroom is it, anyway? Improvisation as a teaching tool. Journal on Excellence in College Teaching, 20(3), 29-60.

Díaz-Rico, L.T. (2013). The cross-cultural language and academic development handbook: A complete $K-12$ reference guide ( $5^{\text {th }}$ ed.). Pearson.

Dray, B.J., \& Wisneski, D.B. (2011). Mindful reflection as a process for developing culturally responsive practices, Teaching Exceptional Children, 44(1), 28-36. http://dx.doi.org/10.1177/004005991104400104

Echevarría, J., Vogt, M.E., Short, D.J. (2013) Making content comprehensible for English learners: The SIOP model. (4th ed.) Pearson Education, Inc.

Ford, B.A. (2004). Preparing special educators for culturally responsive school-community partnerships. Teacher Education and Special Education, 27(3), 224-230. http://dx.doi.org/10.1177/088840640402700302

Ford, B.A., Stuart, D. \& Vakil, S. (2014). Culturally responsive teaching in the $21^{\text {st }}$ century inclusive classroom, Journal of the International Association of Special Education, $15(2), 56-62$.

Ford, B.A., Vakil, S., \& Boit, R. (2016), Family engagement within inclusive settings. In J.P. Bakken, \& F.E. Obiakor (Eds.), General and special education inclusion in an age of change: Roles of professionals involved (Advances in Special Education, Vol. 32)(pp. 75-98). Emerald Group Publishing Limited.

Gay, G. (2002). Preparing for culturally responsive teaching. Journal of Teacher Education, 53(2), 106-116. http://dx.doi.org/10.1177/0022487102053002003

Gay, G. (2010). Culturally responsive teaching. ( $2^{\text {nd }}$ ed). Teachers College Press.

Geenen, S., Powers, L.E., \& Lopez-Vasquez, A. (2001). Multicultural aspects of parent involvement in transition planning. Exceptional Children, 67(2), 265-282. http://dx.doi.org/10.1177/001440290106700209

González, N. (2005). Beyond culture: The hybridity of funds of knowledge. In N. González, L.C. Moll, \& C. Amanti (Eds.), Funds of knowledge (pp. 29-46). Erlbaum.

Hoover, J.J. (2012). Reducing unnecessary referrals: Guidelines for teachers of diverse learners. Teaching Exceptional Children, 44(4), 38-47. http://dx.doi.org/10.1177/ 004005991204400404

Klinger, J., \& Gonzalez, L.S. (2009). Culturally and linguistically responsive instruction for English language learners with learning disabilities. Multiple Voices, 12, 5-20.

Kim, K.H., \& Morningstar, M.E. (2005). Transition planning involveing culturally and linguistically diverse familes. Career Development for Exceptional Individuals, 28(2), 
92-103. http://dx.doi.org/10.1177/08857288050280020601

Ladson-Billings, G. (2009). Toward a theory of culturally relevant pedagogy. American Educational Research Journal, 32, 465-491. http://dx.doi.org/10.3102/ 00028312032003465

Lerner, J. W., Lowenthal, B., \& Egan, R. (2003). Preschool children with special needs: Children at risk and children with disabilities. Pearson College Division.

Lucas, T., Villegas, A.M. \& Freedson-Gonzalez, M. (2008). Linguistically responsive teacher education. Preparing classroom teachers to teach English language learners. Journal of Teacher Education, 59, 361-373. http://dx.doi.org/10.1177/0022487108322110

Merriam, S.B. (2009). Qualitative research: A guide to design and implementation. JosseyBass.

Meyer, D. (2009). The poverty of constructivism. Educational Philosophy and Theory, 41(3), 332-341.

Moll, L., Amanti, C., Neff, D., \& Gonzalez, N. (2005). Funds of knowledge for teaching: Using a qualitative approach to connect homes and classrooms. In N. Gonzalez, L. Moll, \& C. Amanti (Eds.), Funds of knowledge: Theorizing practices in Households, Communities, and Classrooms (pp. 71-88). Lawrence Erlbaum.

Snyder, S. \& Staehr Fenner, D., (2021). Culturally responsive teaching for multilingual learners: Tools for equity. Corwin.

Sorrells, A.M., Rieth, H.J., \& Sindelar, P.T. (2004). Critical issues in special education access, diversity, and accountability. Pearson Education, Inc.

Staehr Fenner, D., \& Snyder, S. (2017). Unlocking English learners' potential: Strategies for making content accessible. Corwin Press.

Stiggins, R., Arter, J., Chappuis, J., \& Chappuis, S. (2006). Classroom assessment for student learning: Doing it right - using it well. Pearson Education.

Turnbull, A.P., Turnbull, H.R., Erwin, E.J., Soodak, L.C., \& Shogren, K.A. (2015). Families, professionals, and exceptionality: Positive outcomes through partnerships and trust. Pearson.

Valencia, R.R. (1997). Conceptualizing the notion of deficit thinking. In R.R. Valencia (Ed.), The evolution of deficit thinking: Educational thought and practice (pp. 1-12). Palmer Press.

Valenzuela, A. (1999). Subtractive schooling: U.S.-Mexican youth and the politics of caring. State University of New York Press.

Weinstein, C., Tomlinson-Clarke S., \& Curran, M. (2004). Toward conception of culturally 
responsive classroom management, Journal of Teacher Education, 55(1), 25-38.

Worrell, F.C. (2007). Ethnic identity, academic achievement, and global self-concept in four groups of academically talented adolescents. Gifted Child Quarterly, 51, 23-38. doi:10.1177/0016986206296655

\section{References for Children's Books}

Bunting, E. (1990). How many days to America? A Thanksgiving Story. Clarion Books.

Lai, T. (2013). Inside out \& back again. New York, NY: Harper.

Paterson, K. (2010). The day of the pelican. Boston, MA: Clarion Books.

Resau, L. (2012). Star in the forest. New York, NY: Delacorte Press.

Senzai, N. H. (2011). Shooting Kabul. New York, NY: Simon \& Schuster.

\section{Authors}

Dr. Shernavaz Vakil is a Professor, Teacher Education Department at Weber State University. Her research and teaching connect practice to theory by linking experiences and voices of individuals with intellectual disabilities to the academic, ethical and social contexts that exist in the classroom.

Dr. Lynn Atkinson Smolen is a Professor Emerita at The University of Akron. She has worked in the field of Teaching English to Speakers of Other Languages (TESOL) for 40 years. Her research and teaching interests include methods for teaching language and literacy, multicultural literature, and culturally responsive pedagogy.

Ms. Jennifer Campbell is a teacher at Westlake Elementary School. She holds an Elementary Education license (1-8), TESOL endorsement, and a Master's Degree in Curriculum and Development. Her research interests include diversity, equity, and inclusion in the classroom.

Dr. Melina Alexander is a professor at Weber State University. She has worked in the field of special education for 30 years. Her research interests include teacher preparation, math education, and social justice. 